\title{
The Strategies of Distribution Channels: Kosovo's Case
}

\author{
Hidajet Karaxha \\ Halit Karaxha \\ University of Tirana, Faculty of Economy, Department Marketing, Tirana, Albania
}

Doi:10.5901/ajis.2015.v4n2p555

\begin{abstract}
Through strategies of distribution channels the firms expect to achieve their goals. The competitor's indifference towards strategies of distribution channels is a great chance for companies that want to try developing the distribution as an essential strategic element of the enterprise. From the data we can see that one of the difficulties in managing the distribution channels is the involvement of businesses and channel members in the unification of strategic objectives and policies. The strategy of designing distribution channels requires knowledge about the needs to design the distribution channel, put and coordinate distribution's objectives, the development of possible alternatives of the channel, the evaluation of variables that affect channel's structure, selecting the best structure and selecting the best member of the channel. The strategies of managing distribution channels require the selection, leadership and motivation of channel members and the evaluation of their success over time. The purpose of this paper is to determine the best distribution channels strategy in kosovar enterprises, which is considered as a link of marketing functions and as a connecting point of creating relationships between enterprises and consumers. Some manufacturing companies use their seduction skills towards channel members and this way these companies manage to sell their products in mass markets. A strategy like this of connecting with powerful motivated partners helps the enterprises to be effective in selling their products. The paper includes empirical data collected through questionnaires and interviews, and secondary data as well based on reviewing the existing literature about issues that have to do with defining the distribution channels strategies. The collection of primary data was conducted through a questionnaire which helped us in creating contacts. The final compilation of the questionnaire, the methodology and samples were realized by analyzing the determining factors that influence the distribution strategies. The research was realized with owners, directors, managers and other enterprise holders in Kosovo. The sample is intentional (not probable).
\end{abstract}

Keywords: defining the strategies of distribution channels, mixed marketing, the strategies of designing distribution channels, the strategies of managing distribution channels.

\section{Defining the Strategies for Distribution Channels}

The strategy of distribution channels can be seen as a special part of the general marketing strategy with which the firm expects to achieve its distribution goals in the target markets. This way, the strategy of marketing channel is related with the aspect of marketing strategy of country (Bert R. $(2004 \& 2013$, p.151). One channel refers to different measures for making a product or service available for the market. In this context, a channel serves as a bridge between the producer and the consumer through which the products reach the target market (Jokinen K.2012, p.14). The distribution strategy is considered as the axis of marketing functions that includes marketing channels, points of option, purchases and focuses on the customer relationship management (Road A., Daryaganj, (2007) p.329). The strategy of distribution channels refers to a wide group of principles through which a firm wants to achieve its distribution objectives by focusing in drafting distribution techniques and methods to achieve the general goals of the enterprise (Mehtaa R., Dubinskyb A., Andersonc R. 2001, p.431). The company has to develop an integrated strategy of distribution channels. It has to evaluate each channel's direct influence in product sales and its transverse effect through other channel interactions or options (Kotler Ph\& Lane Keller K, 2012, p.21). Providing a plan that connects the strategy of distribution channels with individual performance is also a valuable tool in the reduction of conflicts (Kiran V. \&Majumdar M. \& Kishore K., 2012.p.54). The specific objectives included in the relationships between time, cycle, order and sales availability describe the influence of distribution strategies in consumer's value (Aila F., Ondiek G. \& Mise J \& Odera 0 2012, p.1259). An essential element towards company's success is the selection of an appropriate distribution strategy which will increase sales and profit (Nguyen T. 2013, p.14). Distribution strategy is useful in the distribution of effective goods and services with the targeted clients. The company can choose to implement the exclusive strategy of distribution where a retailer receives the right to operate in a certain zone or intensive approach of distribution where a product is available in all possible branches of 
retail sales. This strategy should be followed by the objective to serve the selected markets with a minimal cost while maintaining the desired image of product (Road A., Daryaganj, 2007, P.196).

\subsection{The strategy of distribution channels and the mixed marketing}

Distribution has a great effect in profitability, so a firm should have an excellent and logistic plan of the supply chain and the management of distribution. All variables of mixed marketing are connected with each-other. By raising product's price, the product demand will be reduced and smaller points of distribution will be needed (Singh M., 2012, p.4). Whether the firm sees the distribution issue as worthy of disturbing the high level management or not by developing general strategies and objectives, it still has to face the issue of distribution's role in the mixed marketing. The development of mixed marketing strategies for the product, price, promotion and distribution's place that fulfill market's requirements better than the competitors, is the essence of modern management (Bert R.(2004 \& 2013, p.157). The size of sales force and the number of distribution channels are two vital elements for the enterprise (Koksal M.\& OzgulE., 2007, p.339). The taken decisions in the field of distribution should mostly be in accordance with the decision-making in the field of product (Barcik R., \&Jakubiec M. 2013, p.5). The decisions about selecting the distribution channels include numerous of interconnecting variables that have to be integrated in the strategies of marketing mix. Based on this, the selection of channels can be further defined in the aspect of: distribution coverage, the desired degree of control, the general cost of distribution and channel's flexibility (Donnelly P. 2001, p. 166-171).

\subsection{Channel's strategies and the design of distribution channels}

The design of channels refers to the decisions that come from the organization to create a new distribution channel or from the taken decisions to change an existing distribution channel (Schugk M.2005, p.16). The design of a marketing channel's system includes the analysis of consumers needs, setting the objectives of the marketing channel, identifying the main alternatives of marketing channels and their evaluation (Kotler PH and Lane Keller K. 2009, p. 235). The analysis of consumers needs - the channels produce these service results: space facility, in-time delivery, various products and services advancements. Setting the objectives of the marketing channel - the companies have to set their marketing channel's objectives in terms of the targeted levels of consumer's service. Identifying the main alternatives of marketing channels and their evaluation - after the company has set the objectives of its channel; it also has to identify the main channel alternatives about: the types of mediators, the number of mediators and the responsibilities of every channel member. Evaluating the main alternatives - after the company defines some of channel's options, it has to choose the one that fulfills bets its long-term objectives. Each option must be evaluated based on economic, control and adaption criteria (Kotler P, \& Amstrong G., 2011, p. 351-354).

\subsection{The strategy of marketing channels and its management}

The management of marketing channels requires the selection, management and motivation of individual channel members and the evaluation of their performance over time. The producers distinguish based on their ability to seduce marketing mediators. When the mediators are selected, the company has to define what characteristics distinguish the very best (Kotler P, \& Amstrong G., 2011, p. 354). The manager of channel, in attempt to plan and implement a program that will achieve the cooperation of channel members faces three strategic questions (Bert R.(2004 \& 2013, p.165). 1) How strong must the connection of channel members be? 2) How should the members be motivated to encourage cooperation in achieving distribution objectives? 3) How should mixed marketing be used to achieve this cooperation? Strategic requirements, management preferences and other limits assist in determining the intensity of distribution that offers a better performance of strategic potential. The correct selection of distribution intensity depends on targeting and positioning in the strategies of directing the product and market's characteristics (Road A., Daryaganj, 2007, p.211). The task of managing distribution channels is to coordinate and monitor multiple flows that include mediators, sellers, wholesalers and agents (Rosenbloom B.2010 p.11).

\section{Research Results}

For your company, is the strategy of distribution channels seen as a special part of the general marketing strategy? 
Table 1: The strategy of distribution channels as a special part of the general strategy

\begin{tabular}{cc}
\hline The strategy of distribution channels & $\%$ \\
\hline Yes & $89,6 \%$ \\
No & $10,4 \%$ \\
& $100,0 \%$ \\
\hline
\end{tabular}

Source: Evaluating the authors based on the results of research

Based on the table, $89.9 \%$ of the enterprises said that the strategy of distribution channels is seen as a special part of the general marketing strategy; while $10.4 \%$ don't see it as a special part of the general marketing strategy.

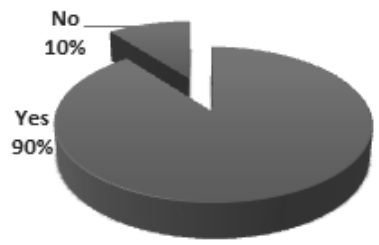

Figure 1: The strategy of distribution channels as a special part of the general strategy Source: Evaluating the authors based on the results of research

What distribution channels does your enterprise use?

Table 2: The use of distribution channels.

\begin{tabular}{cc}
\hline The use of distribution channels & $\%$ \\
\hline Direct distribution channels & $58,8 \%$ \\
indirect distribution channels & $32 \%$ \\
on-line internet channels & $9,2 \%$ \\
& $100 \%$ \\
\hline
\end{tabular}

Source: Evaluating the authors based on the results of research

The leaders of the questioned enterprises said that distribution channels are highly important for their growth and market penetration. From the table we notice that they give high priority to direct distribution channels, $32 \%$ use indirect distribution channels and $9.2 \%$ use the on-line channels believing that these channels will remove their base of consumers.

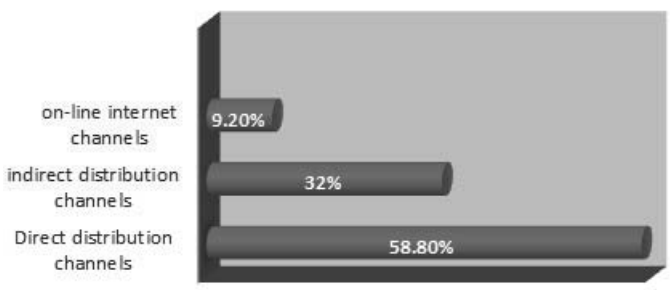

Figure 2: The use of distribution channels

Source: Evaluating the authors based on the results of research

What do you use the strategies of mixed marketing, product, price, promotion and place for? 
Table 3: The use of mixed marketing strategies

\begin{tabular}{lc}
\hline The use of mixed marketing strategies & $\%$ \\
\hline To fulfill the requirements of the target market better than other competitors & $47.2 \%$ \\
To keep a price advantage & $23.4 \%$ \\
To create an advantage in distribution & $19.8 \%$ \\
To create distribution partnerships & $9.6 \%$ \\
\hline
\end{tabular}

Source: Evaluating the authors based on the results of research

Most enterprises said that they use these strategies to fulfill the requirements of target market better than other competitors as an essential element of modern management of marketing, $23.4 \%$ use them to keep the price advantage, $19.8 \%$ use them to create an advantage in distribution and $9.6 \%$ use it to create distribution partnerships. Therefore, these strategies help the enterprises to create relations between satisfying the target market and mixed marketing.

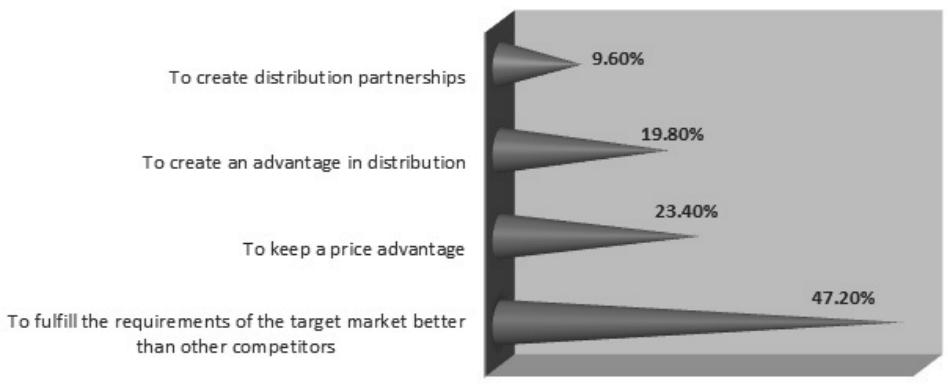

Figure 3: The use of mixed marketing strategies

Source: Evaluating the authors based on the results of research

You select the distribution channels based on which aspect?

Table 4: The selection of distribution channels

\begin{tabular}{lc}
\hline The selection of distribution channels & $\%$ \\
\hline Distribution coverage & $33.6 \%$ \\
The desired degree of control on the distribution channel & $23.4 \%$ \\
The general cost of distribution and & $41.4 \%$ \\
Suitability of distribution channels & $1.6 \%$ \\
& $100 \%$ \\
\hline
\end{tabular}

Source: Evaluating the authors based on the results of research

Revenues from sales and the number of distribution channels are two vital elements for the enterprise to create a competitive advantage compared to other companies. Most of the respondents said that they prioritize distributions costs in choosing distribution channels, $33.6 \%$ prioritized distribution coverage, $23.4 \%$ prioritized the desired degree of control on the distribution channel and only few of them prioritized the suitability of distribution channels. 
Pērshtatshmëris sē kanaleve tē shpërndarjes

The general cost of distribution and

The desired degree of control on the distribution channel

Distribution coverage

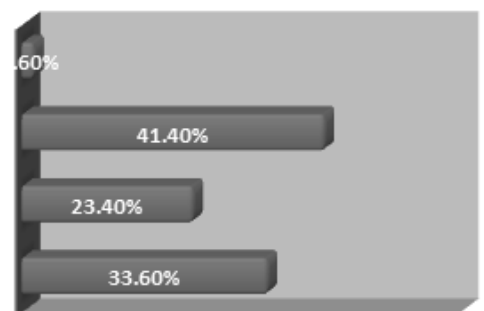

Figure 4: Selecting distribution channels

Source: Evaluating the authors based on the results of research

The decisions for distribution channels design are done through:

Table 5: The decisions for the design of distribution channels

\begin{tabular}{lc}
\hline The decisions for the design of distribution channels & $\%$ \\
\hline Analyzing consumer's needs & $29.7 \%$ \\
Setting the objectives of marketing channels & $23.4 \%$ \\
Identifying the main options of marketing channels & $19.7 \%$ \\
\hline Evaluating the options & $27.2 \%$ \\
\hline
\end{tabular}

Source: Evaluating the authors based on the results of research

From the table we can see that during the design of distribution channels enterprises consider these essential factors: $29.7 \%$ analyzing consumer's needs, $23.4 \%$ setting the objectives of distribution channels, 19.7 identifying the main options of marketing channels and $27.2 \%$ evaluating the options of marketing channels. Therefore, channel's design refers to the decisions that come from the enterprise to create a new distribution channel or the decisions to change an existing one.

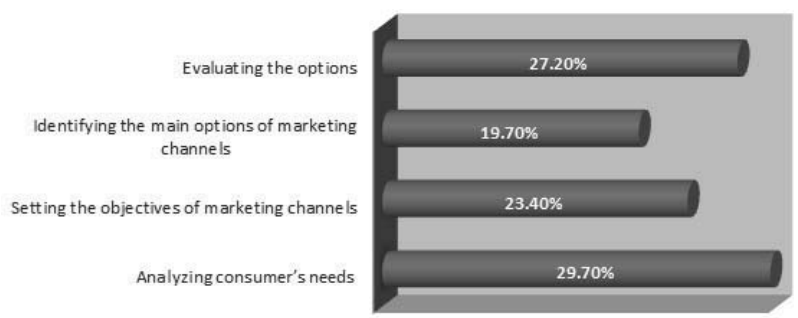

Figure 5: The decisions for the design of distribution channels

Source: Evaluating the authors based on the results of research

Which of the following options are parts of your enterprise's strategy for managing distribution channels?

Table 6: The strategies of managing distribution channels.

\begin{tabular}{lc}
\hline The strategies of managing distribution channels & $\%$ \\
\hline Strengthening the relationship between the members of distribution channels & $39.2 \%$ \\
\hline Motivating channel members & $21.8 \%$ \\
\hline Using mixed marketing to achieve cooperation in distribution & $39 \%$ \\
\hline
\end{tabular}

Source: Evaluating the authors based on the results of research 
Based on the table, we can see how these options indicate the strategies of managing distribution channels: $39.2 \%$ the strategies of managing distribution channels, $21.8 \%$ strengthening the relationship between the members of distribution channels and $39 \%$ the use of mixed marketing to achieve cooperation in distribution.

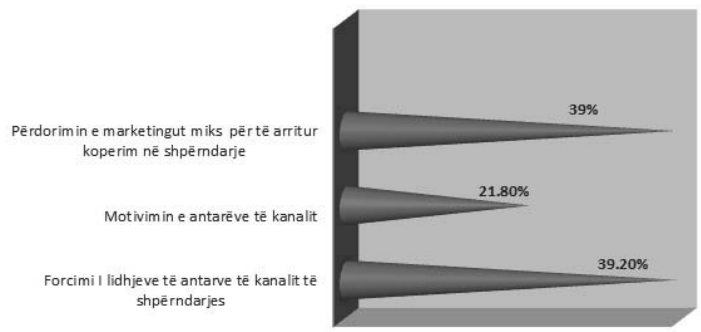

Figure 6: The strategies of managing distribution channels.

Source: Evaluating the authors based on the results of research

\section{Conclusions and Recommendations}

Enterprises must formulate the objectives of their distribution channels in terms of the targeted consumer's service levels. A good strategy of distribution channels affects in achieving the distribution objectives in target markets. Developing strategies of mixed marketing, product, price, promotion and place is a form of connection between satisfying the target market and mixed marketing. From the collected data, it is seen that most enterprises consider the strategy of indirect distribution channels as more effective, while as alternative strategies the use the strategy of on-line distribution channels. Motivating the members of distribution channels and a good management of relationships with partners creates a system of value elaboration which fulfills enterprise's needs and its marketing partner's ones as well. In the management of distribution channels, enterprises should convince the distributors that they can succeed by working together, as part of a cohesive system of value elaboration. It is recommended for the enterprises to define which segments will they serve and choose the best channels to be used at any case. In every segment enterprises should ask to minimize the general cost of the channel. It is preferred for small enterprises in Kosovo to sell their products to retailers while outside the country it is preferred for them to sell their products through distributors.

\section{References}

Bert R. 2004 \& (2013), p.151 " Marketing cheannels"- Drexel University, Thomson, South -western). Jokinen K.(2012), p.14 "Global Sales Channel Strategies of Technology Intensive Startups" Aalto University, P.O. BOX 11000, 00076 AALTO

Road A., Daryaganj, (2007)" Marketing Dynamics- Theory and Practice", Nju Delhi - New Age International (P) Ltd,

Mehtaa R., Dubinskyb A., Andersonc R.( 2001), "Marketing channel management and the sales manager", Industrial Marketing Management

Kotler Ph\& Lane Keller K, (2012), p.21 "Marketing management" 14th ed. Prentice Hall

Kiran V. \& Majumdar M. \&Kishore K., 2012. "Distribution Channels Conflict and Management", Journal of Business Management \& Social Sciences Research (JBM\&SSR) Volume 1, No.1,

Aila F.\& Ondiek G \&Mise J \& Odera O (2012), " impact of channel strategy on customer value of kenyan soft drink companies", interdisciplinary journal of contemporary research in business

Singh M., (2012) " Marketing Mix of 4P'S for Competitive Advantage", IOSR Journal of Business and Management (IOSRJBM)

Haluk Koksal M.\& Ozgul E., (2007), " The relationship betëeen marketing strategies and performance in an economic crisis", The current issue and full text archive of this journal is available at www.emeraldinsight.com/0263-4503.htm

Nguyen T. (2013), "e- business as a distributional strategy", case: veikkaus oy, lahti university of applied sciences

Barcik R., \& Jakubiec M. (2013), " MARKETING LOGISTICS", Doručeno redakci: 16.12.2010; Recenzováno: 2.3.2011; 18.4.2013; Schváleno k publikování: 11.9.2013

Donnelly P. (2001), "Marketing Management, Eighth Edition", @ The McGraë-Hill Companies,

Schugk M. (2005), "Evaluation of Distribution Channels with Portfolio Analysis", Source: Panda; Sahadev

Kotler PH and Lane Keller K. 2009, " A Frameëork for Marketing Management", Fourth Edition, Published by Prentice Hall

Kotler P, \& Amstrong G., (2011), "Principles of Marketing", 14th Edition, Pearson Prentice Hall

Rosenbloom B.(2010). SYMPHONYA Emerging Issues in Management, n. 1, 2010 